\title{
DOS NIÑOS
}

Carlos Franz Thorud 


\section{CARLOS FRANZ THORUD}

Escritor y abogado de la Universidad de Chile. Asistió al taller literario de José Donoso. Agregado cultural de la embajada de Chile en España durante el gobierno de Michelle Bachelet. Entre sus títulos más destacados se encuentran Santiago cero (1988), El lugar donde estuvo el paraíso (1996) y La prisionera (2005). 


\section{DOS NIÑOS}

Agradezco que me inviten a presentar esta Antología Bicentenario de Anales. Soy un escritor de ficciones que -aunque se graduó en la Universidad de Chile- ha trabajado siempre fuera de la Academia, como un free lance (un "lanza libre" sería la traducción exacta; pero me temo que en el dialecto chileno eso me convertiría en un delincuente). Hablar en este Salón me honra. Y también confirma, me parece, la pluralidad de esta Casa de Estudios, abierta incluso a quienes tenemos como posgrados nuestros libros de ficción.

Mi agradecimiento es doble porque esta Antología me permitió confirmar algo atisbado en lecturas anteriores de la revista Anales: la calidad literaria de muchas de sus páginas. No deja de ser una agradable sorpresa, en una publicación académica tan miscelánea. Estilo literario es algo más que "corrección y elegancia" en el lenguaje. Es la capacidad narrativa e incluso poética, característica de aquellos académicos que además de pensar bien, pueden expresarse bien. Y así logran comunicarse más allá del "círculo de tiza caucasiano", que suele encerrar la jerga de sus pares.

Esa capacidad no debiera sorprendernos a los que recordamos que esta Universidad tuvo una fundación poética. Entre las páginas de esta Antología hallamos el testimonio de un niño que presenció el discurso con el cual Andrés Bello, poeta antes que nada, fundó esta casa sobre una sólida base literaria.

Diego Barros Arana, en 1893, describe la instalación de la Universidad, realizada medio siglo antes en el salón de sesiones de la antigua Universidad de San Felipe. Con la habilidad narrativa que echamos de menos en alguna historiografía actual, relata: "Entre los recuerdos más fijos y más gratos de mi niñez, conservo el de esa ceremonia. Los alumnos del Instituto Nacional asistimos en cuerpo. Se nos colocó en rigurosa formación en la parte baja que formaba el centro de la sala. Cuando se hubo leído la lista de los miembros de la nueva corporación (jah!, todos han desaparecido), y cuando aquellos poniéndose de pie y levantando la mano derecha, hubieron prestado el juramento tradicional, se adelantó hasta la mesa presidencial un anciano de talla regular, de facciones finas y correctas, de aire modesto y distinguido. Vestía el traje oficial de la universidad, casaca verde y pantalón blanco, y llevaba al cinto un espadín, como lo llevaban entonces en las ceremonias, muchos de los más pacíficos funcionarios públicos".

Lo más llamativo de esa descripción -creo que convendrán conmigo- es el traje y ese espadín "pacífico", que cargaba Andrés Bello. Si nos impresiona es precisamente porque Barros Arana logra comunicarnos aquello que más deslumbró al niño que era. Ese niño es vagamente consiente de que presencia algo importante. Aunque para él sea mucho más admirable, en ese momento, la casaca verde y el pantalón blanco y el sable de juguete; indumentos que, sobre la facha menuda de Bello, me recuerdan a mí, irresistiblemente, a El Principito. 
El primer rector procede a leer su discurso vestido con ese atavío de Principito: “... todas las verdades se tocan, desde las que formulan el rumbo de los mundos en el piélago del espacio", recita.

Y así ocurre la fundación poética de la Universidad de Chile.

Otros más autorizados han analizado el discurso de Bello en su ideología y programa. Permítanme llamar la atención sobre su estilo poético. Escojamos la misma frase famosa. Atención, por favor, al ritmo de la oración.

"... todas las verdades se tocan, desde las que formulan el rumbo de los mundos en el piélago del espacio; desde las que determinan las agendas maravillosas de que dependen el movimiento y la vida en el universo de la materia; desde las que resumen la estructura del animal, de la planta, de la masa inorgánica que pisamos; desde las que revelan los fenómenos íntimos del alma en el teatro misterioso de la conciencia, hasta las que expresan las acciones y reacciones de las fuerzas políticas; hasta las que sientan las bases inconmovibles de la moral; hasta las que determinan las condiciones precisas para el desenvolvimiento de los gérmenes industriales; hasta las que dirigen y fecundan las artes. Los adelantamientos en todas las líneas se llaman unos a otros, se eslabonan, se empujan".

¿No les recuerda a un soneto, el ritmo de esas frases? Ese fraseo se comporta como un soneto irregular, estructurado en dos cuartetos y un terceto final. La primera "estrofa" desgrana cuatro arranques, cuatro "desdes"; la segunda enumera cuatro conclusiones, cuatro "hastas". La frase final, mucho más corta, termina con el mismo ritmo, la triple adjetivación, que hallamos en la mitad de la larga oración anterior. El párrafo se cierra con tres períodos, reiterativos: "se llaman [...], se eslabonan, se empujan".

Mediante ese ritmo poético eslabonado -un cuasi soneto escondido- no solo entendemos sino que oímos y hasta sentimos, la unidad profunda que Bello pide para la cultura y, en especial, para la Universidad.

(Antes de dejar a Bello, qué poderosas suenan sus frases largas rodando, sin miedo al extravío sintáctico, de punto y coma en punto y coma, cuando las comparamos con nuestra usanza: la frase periodística cortita, que teme desplegarse, el titular flacucho, la declaración televisiva en píldoras, el Twitter, que debiéramos traducir como pío-pío intelectual.)

Lo autores de Anales que han seguido, en general, hermanando claridad de conceptos y belleza de estilo, continuaban una tradición de la que el propio Bello era solo un heredero. Al trabajar así su lenguaje afinaban y potenciaban su pensamiento, aunque luego se demostrara equivocado.

Por ejemplo, un ensayo del Abate Molina, escrito en 1818. Molina creía que los animales africanos son negros. Tan negros, escribe, que "hasta los animales domésticos, inclusos los volátiles, su carne y sus huesos, son negros". Además nos cuenta que "los hijos de los moros y los pollos nacen blancos del todo". Pero luego, producto del intenso sol africano, se ennegrecen. El Abate también sospecha que chilenos y peruanos provenimos de la India, de donde emigramos en tiempos de la invasión de Alejandro Magno. Prueba sería la lengua araucana, "dotada de gran cantidad de vocablos netamente griegos y con la misma significación" lo cual, según Molina, despeja dudas sobre nuestro "origen greco indio". 
Nadie rebaje a mofa o reproche este citar los errores del abate. Del mismo modo que sin fantasía no hay creación artística, sin imaginación no hay ciencia. Molina se equivoca con los africanos y mapuche, pero acierta al proponer que el estrecho de Bering fue la principal vía de población de América, hipótesis hoy la más aceptada.

Lo dicho de nuestro admirable Abate sirve para recordarnos que hasta la más rotunda ciencia actual, mañana podrá ser leída como literatura. Quizás uno de los roles de la narrativa de imaginación sea ese: advertirles a los "autores de razón" la probable caducidad de mucho de lo que dan por seguro.

Para el desarrollo de las ciencias y las humanidades, la transparencia y fuerza con la que nos expresemos puede ser más importante que nuestro error o nuestro acierto. Como pensaba Popper, la hipótesis científica debe prestarse a ser desmentida, más bien que atrincherarse en su verdad transitoria.

El matemático Gabriel Izquierdo, en 1859, examina las cuentas del crimen en Chile aplicando a ellas la teoría de probabilidades y un estilo muy claro. Comparando el número de reos procesados con el de reos rematados o condenados, formula una primera hipótesis. Dice: "Para que se comprenda mejor mi pensamiento, supongo que se acuse a un individuo; como acabamos de ver se podrá apostar 614 contra 386 a que será condenado". No sé a ustedes, pero a mí esa apuesta me pone los pelos de punta. Es algo así como el reverso estadístico de la presunción de inocencia: una vez acusados tenemos más o menos dos posibilidades contra una de ser condenados.

Cuando Izquierdo introduce la variable educación superior en las constantes de sus cuadros estadísticos criminológicos, la cosa mejora (para los educados) y empeora para el resto: "Empleando el método de los cuadrados mínimos he encontrado que la razón... entre la represión del crimen en general y la represión ejercida en particular contra los acusados que han recibido una instrucción superior es la de 11 a l". O sea, el acusado sin educación tenía 11 veces más posibilidades de ser condenado que aquel que la hubiera recibido.

Espero que esas proporciones sean menos válidas casi un siglo y medio después. Pero sospecho que la razón -la ratio- no se ha invertido totalmente. Que no se enteren en ciertas universidades nuevas porque podrían empezar a utilizar este eslogan perverso: si va a delinquir, estudie con nosotros, que así tendrá menos posibilidades de ser castigado.

Antes de terminar su ensayo Izquierdo se lamenta: "Hubiera deseado también considerar la influencia de las estaciones y de las horas del día [en la estadística de crímenes]; sin embargo, no he encontrado datos suficientes para poder deducir matemáticamente los resultados". Díganme ustedes que no es esto, además de ciencia, buena poesía. A Nicanor Parra, gran profesor de esta universidad, seguramente le gustaría.

Siguiendo con la poesía, Anales recoge una conferencia de Gabriela Mistral, dada en Málaga en 1934, donde intenta una "Breve descripción de Chile". El estilo de Mistral, menospreciado por quienes creen que nuestra entonación presente durará más que las pasadas, nos provee de un antídoto eficaz contra los excesos patrióticos del Bicentenario. Dice: "He andado mucha tierra y estimado como pocos los pueblos extraños. Pero escribiendo o viviendo, las imágenes nuevas me nacen siempre sobre el subsuelo de la infancia; la comparación sin la cual no hay pensamiento, sigue usando sonidos, visiones 
y hasta olores de infancia, y soy rematadamente una criatura regional y creo que todos son lo mismo que yo". Es decir, entiendo yo, que al compararnos con otros países no debemos olvidar que vemos según de donde venimos.

La defensa de un estilo literario en la Universidad, puede servir de antídoto, también, contra otros males que la afectan. En 1994, el ex rector, Jaime Lavados Montes, hace una elocuente crítica del "ruido mediático" que entorpece la comunicación razonada de realidades complejas, como la de esta misma institución. Dijo: "El problema sigue siendo cómo dar a conocer nuestro trabajo en una sociedad saturada de comunicación persuasiva, donde la avalancha de mensajes tiende a reducir todo discurso a la categoría de espectáculo [...] y donde sólo descuellan los mensajes marcados por el escándalo o la primicia...".

Me atrevo a proponer una respuesta a ese problema permanente: la Universidad de Chile debe reafirmarse en la crítica a la confusión entre lenguaje y ruido, patente en muchas actividades de nuestra sociedad.

Pero, para que una Universidad pueda "cobrarle la palabra" a nuestra sociedad, debe demostrar que no se la está debiendo a sí misma. En un país donde el 90\% de las personas con educación superior terminada no entiende completamente lo que lee y, por tanto, menos aun puede escribir correctamente [SIALS-Waissbluth], la Universidad debe cuidar el lenguaje en sus propias aulas (quizás promoviendo, entre profesores y alumnos, un manual de estilo). ¿Cómo pretende la Universidad que la sociedad la comprenda si sus propios egresados no son capaces de comprenderse adecuadamente, por escrito?

Actuando así esta Universidad será fiel a su fundación poética, y remediará el posterior pesimismo de don Andrés Bello quien, alguna vez, aconsejó al mismo Barros Arana, ya crecido: "Escriba joven, sin miedo, que en Chile nadie lee".

Anales es para esta Universidad lo que el punto Aleph, soñado por Borges, es para el Universo. Uno de los pocos lugares donde su multiforme actividad puede observarse en su conjunto. Donde las especialidades aun hablando en sus propios dialectos, dejan oír el lenguaje común que las entronca.

Podría seguir citando a otros autores de esta Antología que, sin ser necesariamente poetas, dispusieron de un potente estilo literario: el Dr. Jorge Nicolai, médico, pacifista (y partidario de la eugenesia, todo hay que decirlo) lanzando estupendas ironías (¿por qué la ironía es tan rara entre nosotros? El chiste grueso, la "talla", sí; el sarcasmo cruel, a veces; la ironía menos que poco); el geógrafo Steffen, describiendo cómo, durante el terremoto de 1906, el único sismógrafo de Santiago quedó inutilizado "a causa de la violencia del movimiento que hizo saltar la pluma en medio del sacudimiento más recio..."; o Inés Echeverría, Iris, esta sí escritora, admirando a un historiador quitado de bulla, que era, nos dice: "tan locuaz en la intimidad como silencioso ante los extraños" (iAdmiraríamos hoy a un introvertido, en plena sociedad del exhibicionismo?).

Podría enumerar más líneas felices, pero prefiero terminar estos comentarios como los empecé. Empecé destacando el testimonio de Barros Arana quien, de niño, asistió a la fundación poética de la Universidad. Quisiera terminar citando los recuerdos de otro niño, muy distinto y distante de ese salón y aquella ceremonia, pero al cual la Universidad iba a hermanar en una cultura común de la que esta Antología es prueba. 
En 1910, para nuestro primer centenario, Anales incluye un texto en mapudungun con traducción del propio autor, Manuel Manquilef González. Mestizo de un cacique y una cautiva chilena, Manquilef nació en nuestra frontera no solo geográfica sino cultural y emocional. En esta breve autobiografía Manquilef relata, con insuperable discreción, una escena conmovedora. Criado por su abuela mapuche desde que tenía un año -quien lo cuidó, dice, "como una reliquia de sus esperanzas"-, un día reciben una visita extraña. La escena ocurre por 1895. Cito: "Permaneciendo una tarde a la orilla del fogón de mi ruka, teniendo a mi abuelita en mi frente y estando yo con mis piernas cruzadas raspando una papa para engullírmela con medken, vi repentinamente a una señora con mi padre y que con ansias me contemplaban. La señora me habló y yo corrí a las rodillas de mi abuela, sin entender una palabra del idioma que la chiñurra hablaba. Al día siguiente se me condujo a una escuela pagada en donde [...] aprendí a articular palabritas chilenas".

Hay que imaginarse al cacique y su cautiva en la puerta de esa ruka. Y el miedo del pequeño Manquilef ante el idioma desconocido de su madre, que no era su lengua materna. La larga educación formal de Manquilef, que culminará en la Escuela Normal de Chillán, comienza con ese gesto defensivo del niño que instintivamente corre a refugiarse sobre las rodillas de su abuela de la cual vienen a separarlo. Separarlo de la tierra que conoce y la lengua que sabe, para enseñarle aquello que él describe con ternura y acaso una punta de ironía, como "palabritas chilenas".

Esas dos narraciones, la del niño privilegiado que asistió a la fundación de una Universidad, de la que luego sería rector, y esa otra, la del niño mestizo que no entendía el idioma de su madre, pero que llegaría a ser profesor y puente entre sus dos lenguas, no coinciden por casualidad en las páginas de esta Antología. Son relatos profundamente simbólicos de esta Universidad. Corresponden al espíritu de esta casa. Son verdades que se han llamado, eslabonado y empujado entre sí, para formarla. Aquí se encuentran los extremos de Chile: hablan diferente pero se entienden en un estilo semejante: el del amor y el respeto a la verdad y a la belleza.

Esos dos niños nos sugieren el espíritu de ese estilo. El estilo universitario no está en el orgullo del conocimiento, sino en la humildad ante lo desconocido.

Como la poesía, que es algo más que el mero idioma que la expresa, la sabiduría es algo más que el saber; nace antes y sigue más allá. Está en la distracción maravillada de un niño ante una espadita de juguete, en una solemne ceremonia de fundación. Y está en el recuerdo de un sabio mestizo que aprendió lo esencial de su abuela y de la tierra. Mucho antes de que la escuela y la Universidad le enseñaran a traducirlo, mediante unas cuantas "palabritas chilenas".

Madrid, septiembre de 2010.

Discurso pronunciado en la presentación Antología Bicentenario de Anales de la Universidad de Chile. 